\title{
A INSUSTENTÁVEL SUSTENTABILIDADE DO CAPITALISMO
}

\author{
THE UNSUSTAINABLE SUSTAINABILITY OF CAPITALISM
}

\author{
Graciele Dalla Libera ${ }^{\mathrm{I}}(\mathbb{C}$ \\ Cleide Calgaro II (i) \\ Leonel Severo Rocha III (1)
}

${ }^{\text {I } U n i v e r s i d a d e ~ d e ~ C a x i a s ~ d o ~ S u l, ~ C a x i a s ~}$ do Sul, RS, Brasil. Mestre em Direito.

E-mail: gracieledl@gmail.com

II Universidade de Caxias do Sul, Caxias do Sul, RS, Brasil. Doutora em Ciências Sociais. E-mail: ccalgaro1@hotmail.com

${ }^{\text {III }}$ Universidade de Caxias do Sul, Caxias do Sul, RS, Brasil e Universidade

Regional Integrada do Alto Uruguai e das Missões, Santo Ângelo, RS, Brasil.

Doutor em Direito. E-mail: leonel. rocha@icloud.com

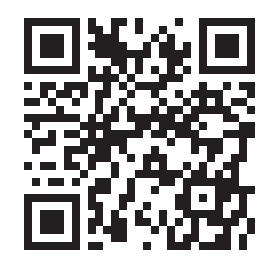

DOI: http://dx.doi.org/10.31512/rdj.v20i38.162

Recebido em: 14.05.2019

Aceito em: 20.02.2020
Resumo: O presente trabalho buscará compreender o que é sustentabilidade e desenvolvimento sustentável, partindo da literatura produzida sobre a temática, bem como, da legislação vigente e dos órgãos governamentais que regulam e fiscalizam a matéria. Após, será abordado brevemente os principais aspectos e contradiçóes do modo de produção que hoje domina as principais sociedades contemporâneas, a saber, o capitalismo. Tecidas tais consideraçóes, serão contrapostos elementos conflitantes no que toca à concepçáo de que se pode ter um desenvolvimento sustentável concomitante com o modo produção capitalista no contexto do direito ambiental. Objetivar-se-á, por fim, evidenciar, através de aportes bibliográficos, que a sustentabilidade do capitalismo é insustentável, configurando-se, em verdade, como apenas um mito dissimulado. $\mathrm{O}$ método da pesquisa é o dialético, na medida em que serăo estudados pares controversos. Serão utilizando-se aportes bibliográficos para dar conta dos objetivos propostos, tais como pesquisa bibliográfica e documental, desenvolvida com base nas produçóes de livros e artigos científicos agregadores do arcabouço teóricometodológico definido, além de legislação pertinente e documentos específicos.

Palavras-chave: Sustentabilidade. Desenvolvimento sustentável. Capitalismo. Direito ambiental.

Abstract: The present work seeks to understand the concept of sustainability and sustainable development, Sterling from the literature om the subject, as well as the current legislation and the governmental body that regulate and supervise the matter. After, will be addressed the main aspects and contradictions of the mode of production that today dominates contemporary societies, the capitalism. Will be contraposed conflicting elements on sustainable development and capitalism in the context of environmental law. Lastly, the objective is to show, through bibliographical contributions, that the sustainability of capitalism is unsustainable, configuring itself, in fact, as just a disguised myth. The method of research is the dialectical, studying controversial pairs. Will be used the bibliographic data to obtain the proposed objectives, such as bibliographical and documentary research, based on 
the production of books and scientific articles aggregated from the theoretical-methodological framework, as well as pertinent and document-specific literature.

Keywords: Sustainability. Sustainable development. Capitalism Environmental law.

\section{Introduçáo ${ }^{1}$}

Com o movimento ambientalista que tomou lugar nos anos 60, especialmente após a comoção pública causada pelo lançamento da obra Primavera Silenciosa de Rachel Carson, em 1962, somado aos temas ambientais debatidos pela primeira vez à nível internacional, na Conferência de Estocolmo em 1972 e, tendo como a "cereja do bolo" o Relatório Brundtland - Nosso Futuro Comum, publicado em 1987, que concebeu a ideia de desenvolvimento sustentável, criou-se uma situação complicada para os exploradores de recursos naturais e principais responsáveis pela degradaçáo da natureza, manterem-se silentes e inertes frente à problemática da crise ambiental.

É dentro deste paradigma que a temática da sustentabilidade e do desenvolvimento sustentável começam a tomar forma. Ambos os conceitos estáo intimamente ligados, na medida em que foram sendo construídos ao longo dos anos tendo a partir do pressuposto de que a proteção do meio ambiente deve acontecer vinculada e concomitante às questóes econômicas, de crescimento, políticas, sociais, culturais, dentre outras.

A partir daí nomenclaturas como ecodesenvolvimento, capitalismo verde e o próprio desenvolvimento sustentável surgiram na literatura especializada. Todos estes conceitos ainda são bastante ambíguos, amplos e, de certo modo, vazios. Na mesma esfera se inclui a ideia de sustentabilidade, que aparece, num primeiro momento, como um princípio normativo, o qual deve ser incorporado às legislaçóes dos países signatários dos principais tratados internacionais sobre meio ambiente.

Contudo, em que pese os esforços teóricos produzidos, as teorias que permeiam a sustentabilidade e o desenvolvimento sustentável encontram óbices e objeções quando questionadas acerca da plausibilidade de concretização de seus ideais na esfera material, vez que, saindo do plano da abstração, a realidade posta se mostra complexa. Nesta esteira, um inimigo comum do meio ambiente, da exploração, da degradação e da própria efetivação da sustentabilidade mostra sua face: o modo de produção capitalista.

O capitalismo, por ter características muito peculiares, como a obtenção de lucro e a acumulação de riquezas, a predominância da propriedade privada, divisão de classes e exploração do trabalho, a exploração da natureza e dos recursos naturais, o crescimento

1 Trabalho financiado pelo Edital 2/2017 da FAPERGS, resultante dos Grupos de Pesquisas (CNPQ): Metamorfose Jurídica, Regulação Ambiental da Atividade Econômica Sustentável (REGA) e Filosofia do Direito e Pensamento Político. 
da desigualdade social e consequente degradação e poluição da natureza em decorrência do consumo excessivo, surge como obstáculo para se alcançar um modo de vida e de produção que possa ser considerado sustentável.

Também, aliado a isso, o capitalismo se utiliza de diversos mecanismos que almejam dissimular e alienar a grande massa de seus reais efeitos, especialmente no que toca ao meio ambiente. Exemplos disso, que seráo abordados no decorrer da pesquisa, englobam a utilização da indústria cultural a seu favor e a prática do greenwashing, os quais se apresentam como ferramentas inteligentes que esse modo de produção encontrou para aliviar as tensões de suas contradições.

Dito isto, a pergunta que guia o presente estudo é a seguinte: o modo de produção capitalista pode ser sustentável?

$\mathrm{O}$ artigo é dividido em três seções. $\mathrm{Na}$ primeira seção, serão abordados e conceituados os termos sustentabilidade e desenvolvimento sustentável, partindo-se dos principais teóricos e estudiosos que pesquisam o assunto. Na segunda seção, será brevemente compreendido o que é e como se dá o modo de produção capitalistas, suas principais características e contradiçóes, e dois mecanismos utilizados para mascarar suas contradiçóes, como o greenwashing e a indústria cultural. $\mathrm{Na}$ terceira seçáo, serão apontados argumentos que sustentam a premissa de que a sustentabilidade, quando proposta e pensada no seio de uma sociedade guiada pelo modo de produção capitalista, é insustentável.

A presente pesquisa será estudada pelo método dialético, vez que busca apontar a realidade não como algo dado e estático, mas sim identificar o processo, os conflitos existentes e as contradiçóes envolvidas na análise do problema. Neste método, serão identificados pares dialéticos que estão em distintos polos da relação. Postulada a tese, será reconhecida sua antítese, para, ao analisar suas relaçóes e interpenetraçóes, chegar a uma nova compreensáo da realidade, que se chama de síntese.

O estudo se dará através da contraposição de elementos conflitantes e a compreensão de seu papel em um fenômeno. Seráo confrontados conceitos tidos como "verdade" com outras realidades e teorias para obter-se uma nova conclusão. O objeto de estudo deste trabalho não é estático, mas sim, será inserido na dinâmica histórica, cultural e social da sociedade contemporânea.

O que se propóe no presente artigo é a necessidade de esclarecimento da problemática que existe por trás do discurso da sustentabilidade, estudada a partir do modo de produção capitalista. $\mathrm{O}$ trabalho não se propóe esgotar o assunto, pelo contrário, apenas tecer breves notas preliminares que visam expandir os horizontes do problema abordado. 


\section{Sustentabilidade e desenvolvimento sustentável}

Segundo o dicionário, a etimologia da palavra sustentabilidade é definida como: “Qualidade, característica ou condição de sustentável.” (MICHAELIS, 2018, p. 347). De início já pode-se perceber a complexidade de delimitar um conceito para uma ideia tão ampla.

A ideia de sustentabilidade surge no contexto da globalização como a marca de um limite e o sinal que busca orientar o processo civilizatório da humanidade. Se constitui, num primeiro momento, como um princípio, de critério normativo para a reconstruçáo da ordem econômica, como uma condição para a sobrevivência humana e um suporte para chegar a um desenvolvimento duradouro, questionando as próprias bases da produção. (LEFF, 2004, p. 15). Segundo Leff: "O conceito de sustentabilidade surge, portanto, do reconhecimento da função de suporte da natureza, condição e potencial do processo de produção.”. (LEFF, 2004, p. 15)

Acerca dos marcos temporais, o termo sustentabilidade deita raízes no século XX, em que pese, como bem colocado por Bosselmann, conceitos de sustentabilidade não foram inventados no final do século XX, mas cerca de 600 anos antes, quando a Europa continental sofreu grave crise ecológica (BOSSELMANN, 2015, p. 30/31). Contudo, foi na Conferência das Naçóes Unidas sobre o Meio Ambiente Humano, realizada na Suécia, na cidade de Estocolmo, em 1972, que a delimitação do conceito contemporâneo de sustentabilidade, intimamente ligado aos problemas ambientais, tomou forma.

A Conferência de Estocolmo é considerado a primeira conferência da Organização das Naçôes Unidas sobre o meio ambiente e a primeira reunião internacional de destaque que discutiu as atividades humanas em relação ao meio ambiente, especialmente para questôes relacionadas com a degradação ambiental e a poluição globais.

Nota-se que o conceito de sustentabilidade está estritamente atrelado ao conceito de desenvolvimento sustentável, o qual é abordado e formulado mais especificamente pela primeira vez em 1987, no Relatório Brundtland - Nosso Futuro Comum, relatório redigido pela Comissão Mundial sobre Meio Ambiente e Desenvolvimento, criada em 1983 pela Assembleia das Naçóes Unidas. Ambos conceitos se complementam, na medida em que buscam um fim comum único, a saber, capacidade da sociedade em manter o ambiente natural com as condiçóes de vida e de produção humana, especialmente em consonância com os aspectos econômicos, políticos e sociais.

Nesta esteira, há que se destacar, também, o evento conhecido como Rio 92, em que a Organização das Nações Unidas - ONU realizou, no Rio de Janeiro, em 1992, a Conferência das Naçóes Unidas sobre o Meio Ambiente e o Desenvolvimento (CNUMAD). A CNUMAD a abrigou a chamada "Cúpula da Terra", nome derivado das mediaçóes e acordos ocorridos entre os Chefes de Estado presentes, em que contemplou 
179 países participantes. Naquele evento, os principais atores internacionais acordaram e assinaram a Agenda 21 Global, um programa de ação baseado num documento de 40 capítulos, que constitui uma tentativa de promover, em escala planetária, um novo padrão de desenvolvimento, denominado "desenvolvimento sustentável" (BOSSELMANN, 2015, p. 59).

Mas superadas as raízes do termo e da ideia de sustentabilidade, questiona-se, o que se entende por sustentabilidade. Veiga assevera que a sustentabilidade se apresenta como carro-chefe de um processo de institucionalização que insere o meio ambiente na agenda política internacional, além de fazer com que essa dimensão passe a permear a formulação e a implantação de políticas públicas em todos os níveis nos Estados nacionais e nos órgãos multilaterais e de caráter supranacional. (VEIGA, 2010, p. 164). Contudo, o autor também é enfático em destacar o caráter inacabado e em construção do conceito:

A sustentabilidade não é, e nunca será, uma noção de natureza precisa, discreta, analítica ou aritmética, como qualquer positivista gostaria que fosse. Tanto quanto a ideia de democracia - entre muitas outras ideias táo fundamentais para a evoluçâo da humanidade -, ela sempre será contraditória, pois nunca poderá ser encontrada em estado puro. (VEIGA, 2010, p. 165).

Além da problemática do conceito aberto, a sustentabilidade apresenta outros problemas, como, por exemplo, a forma em que ela pode ser medida. Segundo Veiga (VEIGA, 2010, p. 173), atualmente há um movimento internacional liderado pela Comissão para o Desenvolvimento Sustentável (CSD) das Nações Unidas, cujo objetivo é construir indicadores. Neste movimento, foram reunidos governos nacionais, instituiçóes acadêmicas, ONG's, organizaçôes do sistema das Naçôes Unidas e especialistas de todo o mundo, em que pretende-se pôr em prática os capítulos 8 e 40 da "Agenda 21", os quais dizem respeito a integração entre meio ambiente e desenvolvimento sustentável na tomada de decisóes (capítulo 8) e a informação para tomada de decisóes (capítulo 40). O autor também destaca que os índices compostos por várias dimensóes (que, por sua vez, resultam de diversas variáveis) costumam ser contraproducentes, para não dizer enganosos ou traiçoeiros, mas sublinha que um bom termômetro de sustentabilidade são os índices de desenvolvimento, conhecidos como IDH (VEIGA, 2010, p. 174).

De outra banda, Sachs traz um conceito mais fechado de sustentabilidade, referindo que a sustentabilidade detém alguns critérios e dimensóes para que possa se constituir. Tais elementos são: social, cultural, ecológico, ambiental, territorial, econômico e político, na esfera nacional e internacional. (SACHS, 2002, p. 85/88).

$\mathrm{O}$ que se pode extrair das dimensóes elencadas por Sachs é que o meio ambiente se trata de uma interaçáo do conjunto de elementos naturais, artificiais e culturais que propiciem o desenvolvimento equilibrado da vida em todas as suas formas. Essa integração busca assumir uma concepção unitária do ambiente compreensiva dos recursos naturais e culturais. É deste conceito de sustentabilidade que o presente trabalho parte. 
Delimitada o que pode ser compreendido por sustentabilidade, passa-se ao conceito de desenvolvimento sustentável.

Como já mencionado, a partir de década de setenta, especialmente no ano de 1972, esquentaram os debates acerca do progresso econômico sem medida. Na Conferência conhecida como ECO72 emergiram as contradiçóes contrapostas entre o desenvolvimento e crescimento econômico e o meio ambiente. Bosselmann ilustra de maneira certeiras as principais ideias que permeavam aquela época:

O ano de 1972 marcou o ponto de partida. Naquele ano, o Clube de Roma publicou o seu relatório Os Limites do Crescimento, a Conferencia das Naçóes Unidas sobre o Ambiente Humano ocorreu em Estocolmo e o United Nations Environment Programme (UNEO) foi estabelecido em Nairobi. O Clube de Roma viu o crescimento econômico em uma rota de conflito com a sustentabilidade ecológica; o sistema das Naçôes Unidas, entretanto, acreditava na conciliação entre os dois. (Bosselmann, 2015, p. 45).

Importante destacar que o Clube de Roma, em meados da década de 60, elencou alguns pontos relevantes acerca da problemática do crescimento econômico desenfreado, lançando a obra "Os limites do Crescimento", que, em síntese, se apresenta como um relatório que buscou trazer ao cerne do debate mundial as consequências do crescimento rápido da população mundial considerando os recursos naturais limitados (BOSSELMANN, 2015, p. 45).

A respeito da temática suscitada pelo Clube de Roma e as consequências que os estudos desenvolvidos por aqueles intelectuais, o economista brasileiro Furtado, ainda no ano de 1974, contestou tais ideias:

A importância do estudo feito para o Clube de Roma deriva exatamente do fato de que nele foi abandonado a hipótese de um sistema aberto no que concerne à fronteira dos recursos naturais. Não se encontra aí qualquer preocupação com respeito à crescente dependência dos países altamente industrializados vis-à-vis dos recursos naturais dos demais países, e muito menos com as consequências para esses últimos do uso predatório pelos primeiros de tais recursos. A novidade está em que o sistema pôde ser fechado em escala planetária, numa primeira aproximação, no que concerne aos recursos não renováveis. Uma vez fechado o sistema, os autores do estudo se formularam a seguinte questâo: que acontecerá com o desenvolvimento econômico, para o qual estáo a concretizarse, isto é, se as atuais formas de vida dos povos ricos chegam efetivamente a universalizarse? A resposta a essa pergunta é clara, sem ambiguidades: se tal acontecesse, a pressão sobre os recursos não renováveis e a poluição do meio ambiente serial de tal ordem (ou, alternativamente, o custo do controle da poluição seria tão elevado) que o sistema econômico mundial entraria necessariamente em colapso.(Furtado, 1974, p. 19)

Furtado, naquela época, já questionava o que ocorreria com os recursos não renováveis e o próprio meio ambiente, se o desenvolvimento econômico continuasse a crescer na forma como se dá no modo de produção capitalista, e este se universalizasse, consolidando-se em países dominantes e periféricos. $\mathrm{O}$ autor responde tal pergunta 
categoricamente, asseverando que "o sistema econômico mundial entraria em colapso" (FURTADO, 1974, p. 19).

Claramente, naquela época a preocupação primordial dos economistas e líderes mundiais ainda se limitava ao crescimento da economia, dentro da perspectiva capitalista, com a exploração dos recursos naturais e do acumulo riquezas. Dentro deste prisma, a ideia de que eventual finitude dos recursos naturais pudesse ameaçar o contínuo crescimento econômico, acompanhada da era de efervescência dos movimentos ambientalistas em meados dos anos 60, especialmente após o lançamento do livro Primavera Silenciosa (1962), de Rachel Carson, implantou-se no centro das discussóes a problemática de como preservar os recursos naturais e o meio ambiente harmoniosamente com o desenvolvimento econômico capitalista.

É neste contexto que, posteriormente, surge em 1987 uma teoria que buscava a harmonização entre a seara social, econômica e ambiental, visando a garantia de um ambiente saudável para as geraçóes presentes e futuras, a saber, a teoria do desenvolvimento sustentável, elaborada primordialmente no documento "Nosso Futuro Comum”, ou Relatório Brundtland.

O referido relatório traz dados sobre o aquecimento global e a destruição da camada de ozônio. Ao final, elenca uma série de metas a serem seguidas pelos países de todo o mundo - que aderirem ao Relatório - com o fito de evitar o avanço das destruiçóes ambientais e o desequilíbrio climático. Historicamente, esta foi a primeira ideia positivada acerca da possibilidade de um desenvolvimento sustentável (BRUNDTLAND, 1991).

O conceito, elaborado e aperfeiçoado por diversos autores, determina que o desenvolvimento sustentável é dividido em três principais pilares: social, econômico e ambiental. Na busca do desenvolvimento de forma sustentável, busca-se um modelo econômico capaz de suprir as necessidades da geração atual, sem comprometer a capacidade de atender as necessidades das futuras geraçóes. Em outras palavras, o desenvolvimento sustentável é aquele que assegura o crescimento econômico, sem esgotar os recursos para o futuro, em que os agentes, públicos e privados, devem atuar de modo que os pilares coexistam e interajam entre si de forma plenamente harmoniosa (BRUNDTLAND, 1991).

No Brasil, encontra base legal não expressa no artigo 225 da Constituição Federal Brasil, que prevê: "Art. 225. Todos têm direito ao meio ambiente ecologicamente equilibrado, bem de uso comum do povo e essencial à sadia qualidade de vida, impondose ao Poder Público e à coletividade o dever de defendê-lo e preservá-lo para as presentes e futuras geraçóes.”. (BRASIL, CF/88, 1988).

Tal tese surge no âmago de uma sociedade fundada no modo de produçáo de vida capitalista, que não mede esforços no contínuo, desregrado e insensato acúmulo de riquezas, exploraçáo do trabalho e da natureza, da manutenção da propriedade privada, 
do crescimento da desigualdade social, do aumento da poluição, dentro outros males advindos desta forma de produzir a vida.

Bosselmann (2015, p. 51/52) questiona como as necessidades humanas e os objetivos ambientais e de desenvolvimento podem ser exercidos conjuntamente. $\mathrm{O}$ autor refere que:

Existem três grandes problemas com o modelo das duas escalas. Primeiro, porque pressupõe uma separarão entre as esferas ambiental e de desenvolvimento que não existe na realidade. $\mathrm{O}$ desenvolvimento não é uma entidade estática, nem o meio ambiente. O objetivo real do desenvolvimento sustentável, trazer ambas as esferas em conjunto, não pode ser refletido em um modelo que visa o equilíbrio das duas entidades separadas. Em segundo lugar, a dimensão de tempo, tão essencial para a sustentabilidade, está faltando no modelo preocupado com o equilíbrio presente. [...] Terceiro, a teoria da igual importância é táo ideologicamente tendenciosa. Ela reflete a equaçáo liberal e neoliberal do desenvolvimento com crescimento econômico e prosperidade. Essa equação não é necessariamente relevante para todos os povos que vivem agora, por exemplo, no "Sul", ou no futuro. (BOSSELMANN, 2015, p. 51).

Em apertada análise, a teoria do desenvolvimento sustentável se propóe a minimizar os impactos ambientais adversos e manter a integridade global do ecossistema, bem como dita ser possível que a exploração dos recursos naturais, os interesses econômicos e investimentos, os avanços tecnológicos e mudanças institucionais se harmonizariam e reforçariam o potencial presente e futuro, com o fito de garantir as necessidade e aspiraçóes de geraçóes distintas. (SILVEIRA, 2014, p. 148).

Em suma, a teoria do desenvolvimento sustentável tem bases oscilantes e indeterminadas, partindo de conceitos abertos e não delimitados. Por isso, tal tese é ostensivamente criticada, tanto à época em que foi trazida cunhada, como nos dias atuais.

O presente trabalho utiliza como base o conceito construído primeiramente pelo Relatório Brundtland, o qual assevera que desenvolvimento sustentável, em essência, é um processo de transformação no qual a exploração dos recursos, a direção dos investimentos, a orientaçáo do desenvolvimento tecnológico e a mudança institucional se harmonizam e reforçam o potencial presente e futuro, a fim de atender às necessidades e aspiraçóes humanas, presentes e futuras.

Tecidas tais considerações e delimitados, na medida do possível, os conceitos de sustentabilidade e desenvolvimento sustentável, passa-se a tentar compreender as principais características do modo de produção capitalista, e quais as implicaçóes que tal sistemática resulta sobre o meio ambiente.

\section{0 modo de produção capitalista}

Sabe-se que toda sociedade se organiza de forma a ver assegurada uma coisa fundamental: a sobrevivência. Dentro do conceito de sobrevivência, inserem-se alguns 
elementos fundamentais, como a capacidade e possibilidade de alimentação, moradia, segurança, dentre outros. Este modo de conseguir e produzir as coisas se denomina modo de produção.

Ao longo dos séculos, a humanidade experimentou diversos modos de produção, como o modo indígena, feudal, cooperativista, dentro outros já catalogados (GUARESCHI, 1986, p. 38). Atualmente, o modo de produçáo dominante e determinante da sociedade contemporânea, a nível global, é o capitalismo.

O modo de produção capitalista foi densamente estudado por Karl Marx, na obra O Capital, sendo esta uma obra inacabada (HARNECKER, 1978, p. 22). O presente trabalho não se propóe ao aprofundamento dos principais conceitos trazidos por Marx na obra para a perfeita compreensão do modo de produção capitalista, mas apenas breves esboços acerca da forma como este modelo econômico se constitui, apontando-se os principais aspectos e particularidades que lhe são inerentes.

Acerca do conceito de modo de produçáo, imperioso que se faça um breve arrazoado. Segundo Harnecker (1978, p. 14), o conceito de modo de produção se traduz num conceito teórico que permite pensar a totalidade do social, portanto, se constitui por uma estrutura global formada por três estruturas regionais, a saber, econômica, jurídicopolítica e ideológica. A autora também elucida que o conceito de modo de produção é um termo empregado por Marx e Engels para descrever a forma de produção de bens materiais (HARNECKER, 1978, p. 12).

No mesmo sentido, Harnecker (1978, p. 16) elucida que o núcleo estruturador do modo de produção são as relaçóes de produção, na medida em que essas relaçóes explicam o tipo característico de articulação das distintas estruturas regionais de cada modo de produção, e serão elas que determinarão qual ocupará o papel dominante.

Em apertada síntese, pode-se dizer que as forças produtivas dos diferentes modos de produção são basicamente semelhantes. Contudo, o que distingue um do outros são as relações de produção, ou seja, como o capital e o trabalho se relacionam (GUARESCHI, 1986, p. 38). Nesta esteira, segundo o dicionário, capitalismo é definido como:

Influência ou supremacia do capital; Organização econômica em que as atividades de produção e distribuição, obedecendo aos princípios da propriedade privada, da competiçáo livre e do lucro, produzem uma divisão da sociedade em duas classes antagônicas, porém vinculadas pelo mecanismo do mercado: a dos possuidores dos meios de produção e a do proletariado industrial e rural. [...] (MICHAELIS, 2018, p. 128).

Para compreender o que institui o modo de produção capitalista, Guareschi dá um exemplo bastante pertinente, tomando por exemplo uma fábrica, ou terra, e questionando: 
Pergunta-se: Qual a relação entre as pessoas? São todas iguais? A resposta é: não. Por quê? Porque uns são os donos do capital e os outros trabalham. Isto é: existem alguns que são proprietários e outros só trabalham. A palavra "dono", em latim, é "dominus". Costumase dizer então que a relação entre as pessoas é de "dominação".

$[\ldots]$.

Agora, qual a relaçáo entre o trabalho e o capital? Seria capaz de adivinha? Pense um pouco. Para entender o nome que vamos dar a essa relação é preciso alguma coisinha mais. E essa coisinha é: o que dá valor a todas as coisas? (Guareschi, 1986, p. 39)

De igual modo, acerca do capitalismo, Altvater assevera:

Mas até em O capital, o conceito de "capitalismo" aparece apenas uma única vez. No segundo volumo afirma-se o seguinte: "[...] o capitalismo já está contido (aufgehoben) no fundamento pelo pressuposto da fruição atuar como motivo propulsor, não o próprio enriquecimento [...]" (MEW, vol. 24, p. 123). O motivo e fator que movem o capitalista são, portanto, o enriquecimento, não a fruição. $\mathrm{O}$ valor de troca domina sobre o valor de uso. Para Marx, "capitalista" é o atributo do modo de produçáo ou do conjunto das formas sociais, que ele denomina "formação social" e que se distinguem pelo enriquecimento ou, como diríamos hoje, pela avidez, pela cobiça e pela avareza, não pelo motivo hedonista de gozar a vida. (Altvater, 2010, p. 63/64)

Pode-se dizer que o capitalismo é um modo de produzir a vida, através das relações de produção, isto é, a produção e a troca de bens e serviços. Uma economia capitalista reúne três elementos-chave, que a definem: a propriedade privada dos meios de produção, o mercado de trabalho e a troca de produtos num mercado visando ao lucro.

No capitalismo, a produção sempre visa ao lucro. Em outros modos de organizar a economia, a produção não visa necessariamente ao lucro, mas saciar necessidades básicas dos produtores e membros da comunidade ou simplesmente disponibilizar bens e serviços. A obtenção do lucro é imanente ao capitalismo (CATANI, 1986).

Ou seja, o que se percebe é que o capitalismo, por ter características muito intrínsecas, como a obtenção de lucro e a acumulação de riquezas, a predominância da propriedade privada, divisão de classes e exploração do trabalho, a exploraçáo da natureza e dos recursos naturais, o crescimento da desigualdade social e consequente degradação e poluição da natureza em decorrência do consumo excessivo, surge como obstáculo para se alcançar um modo de vida e de produção que possa ser considerado sustentável.

Logo, a relação entre os males causados pelo modo de produção capitalista em face do meio ambiente é palpável. Dos efeitos negativos, destaca-se a exploração quase que irrestrita dos recursos naturais e a poluição em escala global. Vislumbra-se que está em curso um processo de exaustáo dos recursos naturais, o qual, nos moldes como vem sendo feito, caso não seja freado resultará na frequência de desastres naturais, aumento do nível do mar, secas e inundações, eliminação gradual da biodiversidade. Além disso, há que se destacar as consequências socioeconômicas decorrentes deste processo, como fome, guerras, migraçóes em massa, doenças, entre outros. 
Outro ponto, em que pese não ser o objeto principal do presente trabalho, merece ênfase, qual seja, a produção e utilização em massa de agrotóxicos, especialmente na esfera da alimentação. Em razão do modelo químico-dependente de agrotóxicos, a cadeia do agronegócio se configura como um processo de insustentabilidade ambiental, vez que são manuseados componentes extremamente nocivos à saúde. Inúmeros estudos recentes acerca da temática apontam para intoxicaçóes humanas, cânceres, más-formaçóes, mutilações, sequelas e ainda contaminação com agrotóxicos e fertilizantes químicos das águas, do ar, da chuva e do solo em todos os espaços ou setores da cadeia produtiva do agronegócio. Cita-se a seguir um desses exemplos.

Bombardi, em estudo publicado em 2011 acerca da intoxicaçáo e morte por agrotóxicos no Brasil, através de análise do Anuário do Agronegócio 2010 (GLOBO RURAL, 2010), pode concluir que o uso de agrotóxico nos moldes em que vem ocorrendo Brasil tem sido altamente nefasto, do ponto de vista ambiental, socioeconômico e sanitário. Os dados apresentados no trabalho se mostram de extrema gravidade, na medida em que os camponeses, trabalhadores rurais, os familiares destes trabalhadores e moradores de áreas próximas aos cultivos contaminados com agrotóxicos estão sendo intoxicados cotidianamente de forma direta (BOMDARDI, 2011).

O interesse privado sobre a produçáo cada vez maior de agrotóxicos é lógico: a população necessita de alimentos, logo, a produção de alimentos precisa do uso de agrotóxicos para eliminar e controlar insetos, doenças, ou plantas daninhas que causam danos às plantações. Assim, a conclusão é que certamente a margem de lucro sobre a utilização em escala global destes venenos será altamente positiva ao dono deste meio de produção.

Desta conjectura, pode-se presumir que entre capitalismo e sustentabilidade existem algumas contradiçôes. Além de todos os impasses já mencionados, este modo de produção detém alguns mecanismos sutis de alienação das grandes massas, no que toca ao mascaramento de seus efeitos funestos.

Um deles é a indústria cultural, conceito elaborado por Theodor Adorno e Max Horkheimer. Segundo os filósofos (2006, p. 103/104), na indústria cultural, os produtos não mais representam um tipo de classe - superior ou inferior, dominantes e dominados mas são exclusivamente dependentes do mercado. Este termo designa um modo de fazer cultura, a partir da lógica da produção industrial. Quer dizer, toda a produção artística fica padronizada e não há espaço para o novo. A indústria cultural desenvolveu-se com o predomínio que o efeito, a performance tangível e o detalhe técnico alcançaram sobre a obra. Adorno e Horkheimer referem que:

A violência da sociedade industrial instalou-se nos homens de uma vez por todas. Os produtos da indústria cultural podem ter a certeza de que até mesmo os distraídos vão consumi-los alertamente. Cada qual é um modelo da gigantesca maquinaria econômica 
que, desde o início, não dá folga a ninguém, tanto no trabalho quanto no descanso, que tanto se assemelha ao trabalho. (ADORNO; HORKHEIMER, 2006, p. 105).

Um exemplo de como o capitalismo se utiliza da indústria cultura, é a forma como apresenta o agronegócio. Grandes veículos de mídia anuncia o modelo de agronegócio como algo inovador, com o famoso jargão "Agro é tech, agro é pop"2.

Adorno e Horkheimer (2006, p. 106) demonstram que a capacidade rara de satisfazer minuciosamente as exigências do idioma do telespectador através da indústria cultural torna-se padrão de competência neste meio. E como bem frisam: "Na indústria cultural, porém, os menores elementos do tema têm origem na mesma aparelhagem que o jargão no qual é acolhido". (ADORNO; HORKHEIMER, 2006, p. 107).

Outro instrumento do capitalismo de extrema relevância e bastante em voga atualmente é a técnica conhecida como greenwashing.

Segundo o Cambridge Dictionary, o greenwashing tem por conceito "to make people believe that your company is doing more to protect the environment than it really is". Também, em tradução literal do termo, seria uma forma de "lavagem verde" de produtos e mercadorias. Trata-se se uma prática que vincula a ideia de sustentabilidade ambiental à publicidade de produtos e serviços que, em verdade, nada possuem de sustentáveis.

O greenwashing tem como objetivo criar uma imagem positiva diante da opinião pública, ocultando ou desviando a atenção de impactos ambientais negativos por elas gerados. O termo está diretamente associado às açôes de marketing que são elaboradas por governos, empresas ou organizaçōes corporativas para enfatizar suas atividades com boas práticas ambientais, minimizando os impactos ambientais negativos da linha de produção ou valorizando indevidamente o produto ou mercadoria (VIDAL DE SOUZA, 2017).

Em suma, o greenwashing cria um modelo falso acerca de supostos produtos sustentáveis, e deturpa a realidade, promovendo discursos de sustentabilidade e desenvolvimento sustentável, quando, em verdade, tudo se resume a angariar benefícios ambientais de um produto ou marca.

Tecidas as consideraçóes necessárias acerca do modo de produção capitalista e de alguns de seus instrumentos de alienação das massas e mascaramento da realidade, passase a argumentar sobre a (in)sustentabilidade capitalista.

2 A propaganda comercial que veicula a chama "Agro é pop, agro é tech" pode ser acessada através do seguinte link: https://www.youtube.com/watch?v=pQOp0Bv8KZE. Acesso em 10 jul 2018.

3 Em traduçáo livre: "fazer as pessoas acreditarem que a sua empresa está fazendo mais para proteger o meio ambiente do que de fato está.". Disponível em: https://dictionary.cambridge.org/pt/dicionario/ingles/greenwash. Acesso em 09 out 2018. 


\section{A sustentabilidade insustentável do capitalismo}

Como muito bem destacado por Altvater (1995, p. 21), o desenvolvimento se realiza no espaço global, mas de modo extremamente descontínuo e não simultâneo nas diversas naçóes e regióes globais. Algumas das sociedades altamente industrializadas estão se modificando em países pós-industriais, logo, enquanto encarnação de modernização e de progresso, a industrialização torna-se parcialmente obsoleta, tomando certamente um significado diferente. Outros países procuraram recuperar o atraso na industrialização somente há poucas décadas.

O ideal de desenvolvimento, nos moldes do capitalismo e signo dos países ricos e altamente industrializados, não parece ser possível que se espalhe pelo mundo inteiro, como um modo de vida e de trabalho, na medida em que: em primeiro lugar, se baseia em um elevado consumo energético e material; em segundo, precisa dispor de sistemas energéticos e de transformaçăo material eficientes e inteligentes; e, em terceiro, precisa realizar e organizar nesta base uma prática de vida europeia-ocidental, com os correspondentes modelo ideológicos e de pensamento e instituiçôes políticas e sociais reguladoras. (ALTVATER, 1995, p. 25).

Altvater (1995, p. 28) também tece críticas ao fantástico ideal de crescimento burguês decorrente da industrialização dos países ricos, que acabam suscitando nos países periféricos a aspiraçáo de atingirem o fantasioso nível de desenvolvimento tal qual os países ao Norte. $\mathrm{O}$ autor diz que: "A industrialização constitui um bem oligárquico [...]: nem um sequer dos habitantes da Terra pode gozar as benesses da sociedade industrial afluente, sem que todos os homens sejam colocados numa situação pior do que aquelas em que se encontravam antes.". E mais:

O moderno sistema industrial capitalista depende de recursos naturais numa dimensão desconhecida a qualquer outro sistema social na história da humanidade, liberando emissôes tóxicas no ar, nas águas e nos solos e, portanto, também na biosfera. Nestes termos, necessita de recursos naturais (energias e matérias-primas e também cada vez mais das fontes genéticas localizadas sobretudo no Sul) e precisa de "recipientes" (locais de despejo onde os rejeitos gasosos, líquidos e sólidos possam ser absorvidos ou depositados) (ALTVATER, 1995, p. 28-29).

Isto é, a sustentabilidade que se propóe no capitalismo é sempre pensada a partir da exploraçáa, da acumulaçáo de riquezas e lucros, na proteçáo da propriedade privada, pois aspectos intrínsecos desse modo de produção. Parece ser inescapável que qualquer medida a ser tomada se guie por interesses do capital e das grandes oligarquias e oligopólios que dominam a economia mundial.

Sobre este aspecto é que agem, primordialmente, ferramentas como o greenwashing e as técnicas da indústria cultural na apropriaçấo da mística de um desenvolvimento sustentável, dentro outros tantos instrumentos nefastos que o capital utiliza. 
Já no que toca ao discurso da sustentabilidade e do desenvolvimento sustentável, Leff ensina que:

O discurso da sustentabilidade busca reconciliar os contraditórios da dialética do desenvolvimento: o meio ambiente e o crescimento econômico. Este mecanismo ideológico não significa apenas uma volta de parafuso a mais da racionalidade econômica, mas opera uma volta e um torcimento da razão; seu intuito não é internalizar as condiçóes ecológicas da produção, mas proclamar o crescimento econômico como um processo sustentável, firmado nos mecanismos do livre mercado como meio eficaz de assegurar o equilíbrio ecológico e a igualdade social. O discurso do desenvolvimento sustentável pressupóe que a economia entrou numa fase de pós-escassez, isto é, que a produção, como base da vida social, foi superada pela modernidade. Esta estratégia discursiva desloca a valorização dos custos ambientais para a capitalização do mundo como forma abstrata e norma generalizada da sociedade. (LEFF, 2001, p. 27).

O autor também assevera que o discurso oficial do desenvolvimento sustentável penetrou nas políticas ambientais e em suas estratégias de participaçấo social, e dali convida diferentes grupos de cidadãs (empresário, acadêmicos, trabalhadores, indígenas, trabalhadores rurais) a somar esforços para construir um futuro comum. Contudo, destaca que esta operação de cooperação que busca integrar os diversos atores do desenvolvimento sustentável, em verdade, dissimula seus interesses diversos num olhar especular que converge para a representatividade universal de todo ente no reflexo do argênteo capital (LEFF, 2001, p. 28).

Outro argumento de relevância que merece ênfase são as medidas que o relatório Brundtland reivindica para que se alcance o desenvolvimento sustentável, dentre elas a limitação do crescimento populacional, garantia de recursos básicos em longo prazo, preservação da biodiversidade e dos ecossistemas, diminuição do consumo de energia e desenvolvimento de tecnologias que admitem o uso de fontes energéticas renováveis, aumento da produção industrial nos países não industrializados com base em tecnologias ecologicamente adaptadas, controle da urbanização desordenada e integração entre campo e cidades menores, dentre outra. Tais reinvindicaçóes beiram à utopia. Leis aduz que:

O conjunto de medidas que o relatório reivindica (limitação do crescimento populacional, garantia de alimentação a longo prazo, preservação da biodiversidade e dos ecossistemas, diminuição do consumo de energia e desenvolvimento de tecnologias de fontes renováveis, crescimento econômico equilibrado nos países industrializados ecologicamente, controle da urbanização selvagem, satisfação de necessidades básicas para todos os seres humanos, etc.) obrigaria a revisar em profundidades os valores e práticas tradicionais das atuais instituiçóes políticas e econômicas nacionais e internacionais. (LEIS, 1999, p. 152).

E possível vislumbrar que apenas a implementação de medidas e políticas públicas que visem a concretizaçáo de tais reivindicaçóes náo serão suficientes para forçarem o mínimo de mudanças. Isto é, ou se mudam os valores e o modo de produção da sociedade, 
ou estará presente no horizonte da humanidade cada vez mais delineada a eclosão do sistema natural em detrimento do ser humano e da vida na terra.

Não bastassem os pontos já suscitados, outro obstáculo surge para a concretização de uma forma de sustentabilidade no capitalismo: os custos. Como aponta Altaver (2010, p. 169), os efeitos negativos da poluição atmosférica e aquática, somados ao desrespeito pelas condiçóes naturais de segurança alimentar, a utilização excessiva dos oceanos e a erosão de terras, manifestam importância para as condiçôes de reprodução da força de trabalho. O autor aduz que "Os custos da redução da poluição atmosférica e do tratamento de efluentes líquidos pertencem aos gastos de capital e, por conseguinte, aumentam o capital fixo constante, gerando uma composição crescente do capital orgânico e uma margem decrescente de lucro." (ALTAVTER, 2010, p. 168).

Ou seja, há que se questionar: qual o interesse do capital em dispender custos econômicos para proteger o meio ambiente? Ou melhor, há interesse? E se há interesse, quais são as razóes fundantes para tal? A preocupação é, de fato, com a natureza, ou apenas com as formas possíveis de lucrar sobre ela? Esses são alguns questionamentos pertinentes que merecem serem seriamente debatidos.

Dentro desta esfera de raciocínio, importante citar o princípio do poluidorpagador. Trata-se de um princípio normativo de caráter econômico, tendo em vista que imputa ao poluidor os custos relacionados a uma atividade poluente, arcando o poluidor com as despesas da reparação do dano por ele causado ao meio ambiente (MONTIBELLER-FILHO, 1999, p. 62).

A Lei no 6.9388/1981, que dispóe acerca da Política Nacional de Meio ambiente, em seu artigo $4^{\circ}$, inciso VII, prevê expressamente o princípio do poluidor-pagador, qual seja: "[...] à imposição, ao poluidor e ao predador, da obrigação de recuperar e/ou indenizar os danos causados e, ao usuário, da contribuição pela utilização de recursos ambientais com fins econômicos.” (BRASIL, Lei 6.9388, 1981).

A questão de valoração econômica, por si só, já é problemática. Mas, para além disso, imperioso pensar que, dentro da lógica que domina o modo de produçáo capitalista, se ao poluidor lhe será apenas atribuída uma contraprestação financeira para que continue desempenhando sua atividade, independente do estrago que vier a causar, será que este mesmo poluidor não pensará que, apesar da eventual degradação ambiental, o lucro que advir de tal poluição não lhe será maior que a penalidade aplicada? Esta é, precisamente, a lógica do capital.

Montibeller-Filho tece algumas considerações pertinentes acerca da temática:

[...] as proposiçóes ambientalistas conservadoras do sistema de mercado - que o defendem ou toleram - constituem-se contribuiçóes relevantes para amenizar os efeitos da problemática socioambiental: todavia, não conseguem superar a contradição fundamental do sistema de tender a apropriar-se de forma degenerativa dos recursos naturais (esgotamento) e do meio ambiente (degradação), impossibilitando que sejam 
concretizadas as equidades sociais e ecológicas intra, intergeracional e internacional do desenvolvimento sustentável. O desenvolvimento sustentável revela-se um mito, compreendendo dupla dimensionalidade: o caráter universal, ao contemplar a reflexão, pela maioria dos povos - do mundo capitalista ou não -, e de uma condição de equidade socioeconômica e ambiental desejada, dando elementos para a construção de projeto civilizatório em diferentes culturas, norteador de práticas sociais (conflituosas); e o caráter particular, sendo no sistema atualmente dominantes, e nas condiçóes analisadas de tendência secular e escala global, todavia, uma ideia sem correspondência direta, até contraditória, com a realidade. Este aspecto contribui na compreensão da sociedade capitalista e seus limites em concretizar ideias socialmente construídas. (MONTIBELLER-FILHO, 1999, p. 243-244).

O que, sucintamente pode-se extrair é que a preocupação com a chamada crise ambiental cresce na tentativa de responder às contradições impostas pela própria lógica do modo de produção capitalista. Ao costurar cooperações entre o desenvolvimento sustentável, a governança corporativa e a responsabilidade social empresarial e uma ideologia dominante da realidade posta, constrói uma visão de mundo coerente a este "mascaramento", oferecendo alternativas que são simplesmente incapazes de superar as contradições sociais e ambientais tal como se pretende.

A ideia de sustentabilidade é adversa dos elementos imanentes que constituem o capitalismo na sua raiz. Questiona-se como pode haver sustentabilidade ambiental quando o modo de produção da sociedade contemporânea se alicerça em práticas de exploração e esgotamento dos recursos naturais, poluição em escala global, prevalência da propriedade privada, o consumo excessivo, a visão central da obtenção de lucro, dentre outras características do capitalismo, as quais são inteiramente opostas aos valores que guiam as práticas sustentáveis. Leff diz:

A retórica do desenvolvimento sustentável converteu o sentido crítico do conceito de ambiente numa proclamação de políticas neoliberais que nos levariam aos objetivos do equilíbrio ecológico e da justiça social por uma via mais eficaz: o crescimento econômico orientado pelo livre mercado. Leff, 2010, p. 24).

Isto é, parece incongruente que sejam alcançados níveis de sustentabilidade reais, e não apenas nos países ricos, enquanto a economia mundial dominante se reduz ao capitalismo. Se o livre mercado e o crescimento econômico guiam as medidas a seres tomadas para alcançar a sustentabilidade ou uma forma de desenvolvimento, o raciocínio lógico é tarefa fácil: os interesses do livre mercado e dos grandes investidores que visam crescimento se resumem em acumulação de lucro e capital.

Ademais, sempre importante sublinhar que a degradação do natural náo atinge todos os homens e mulheres indistintamente. A degradação não é linear, simples e contínua, pelo contrário, é consubstanciada em elementos contraditórios intimamente ligados aos jogos de poder entre dominantes e dominados ao longo da história humana. 
Contudo, àqueles vivem à margem sempre serão as maiores vítimas da superexploração. Portanto, também se torna imperioso questionar: sustentabilidade para quem?

Em suma, por suas próprias contradições, vê-se que o modo de produção capitalista é avesso aos preceitos fundamentais da sustentabilidade.

\section{Consideraçóes finais}

De todo o arrazoado, pode-se concluir que pensar em alguma forma de sustentabilidade ambiental ou desenvolvimento sustentável a ser praticada no seio do modo de produção capitalista soa contraditório. As incompatibilidades verificadas entre os elementos imanentes deste modo de produção com os valores e preceitos que guiam a ideia de sustentabilidade são palpáveis.

Desta forma, a pergunta que guiou o presente estudo, qual seja, "o modo de produção capitalista pode ser sustentável?”, deve ser respondida com outras questóes, a fim de compreender a complexidade que envolve o meio ambiente, a sociedade moderna e o capital.

A partir dos argumentos trazidos no presente estudo, vislumbra-se que o capital, no seu âmago, provavelmente se interessará pelo meio ambiente se este puder lhe dar algum retorno econômico. Proteger o meio ambiente custa caro, e o capital náo extrai vantagem disso.

Desta conjectura, especial destaque merecem os meios que o capitalismo se utiliza para alcançar seus interesses. A indústria cultura, quando manipulada pela conveniência do agronegócio, por exemplo, torna-se um instrumento maligno na propagação de produtos e mercadorias nada sustentáveis. Na mesma linha, o greenwashing surge como a personificação do mascaramento e falseamento de produtos e mercadorias, visando tão somente o lucro sobre a mentira e a ignorância do consumidor.

De todo o exposto, o que se afigura é uma insustentabilidade ambiental em face da produção material da vida nos moldes do capitalismo.

Outrossim, em que pese inúmeros movimentos hoje se preocupem e lutem por uma sociedade sustentável e pela proteção da natureza em microesferas, não parece factível que tal luta obtenha vitória se fragmentada e segmentada da luta maior, que é a superação do capitalismo.

Enquanto este modo de produção insustentável não for combatido concomitantemente com as demais lutas, as providências tomadas até entáo contra a degradação da natureza soam como meras medidas paliativas que apresentam soluçóes momentâneas para um problema perene.

Como afirma Rocha "a sociedade como sistema social é possível graças à "comunicação". Por sua vez, a comunicação depende da linguagem, das funções, da 
diferenciação e das estruturas. Isto torna possível a evolução social, porém decisiva é, neste sentido, a "diferenciação"” (2013, p.38). Desse modo, é preciso que a sociedade repense a sustentabilidade e a forma como a mesma é utilizada no modo de produção capitalista, visto que há a necessidade de uma nova racionalidade ambiental que fortaleça a proteção ambiental e permita que a matriz de desenvolvimento econômico não seja tão predatória. A partir da citação de Rocha, a sociedade, vista como um sistema social, pode através da comunicação vislumbrar uma racionalidade sistêmica de viabilização da sustentabilidade na modernidade, onde a matriz econômica pode ser repensada e reavaliada.

\section{Referências}

ADORNO, T.; HORKHEIMER, M. Dialética do esclarecimento: fragmentos filosóficos. Rio de Janeiro: Zahar, 2006.

ALTVATER, Elmar. O fim do capitalismo como o conhecemos: uma crítica radical do capitalismo. Rio de Janeiro: Civilização Brasileira, 2010.

ALTVATER, Elmar. O preço da riqueza. Sáo Paulo: Editora Universidade Estadual Paulista, 1995.

BOMBARDI, Larissa Mies. Intoxicação e morte por agrotóxicos no brasil: a nova versão do capitalismo oligopolizado. Boletim Dataluta. ISSN 2177-4463. Disponível em: http://www2.fct.unesp.br/nera/artigodomes/9artigodomes_2011.pdf. Acesso em: 7 jul. 2018.

BOSSELMANN, Klaus. O princípio da sustentabilidade. São Paulo: Revista dos Tribunais, 2015.

CATANI, Afrânio Mendes. O que é capitalismo. 21 ed. São Paulo: Brasiliense, 1986.

CAMBRIDGE DICTIONARY. Cambridge English Dictionary e Thesaurus. Disponível em: https://dictionary.cambridge.org/pt/dicionario/ingles/greenwash. Acesso em: 6 jul. 2018.

COMISSÃO MUNDIAL SOBRE MEIO AMBIENTE E DESENVOLVIMENTO. Nosso Futuro Comum. 2 ed. Rio de Janeiro: Fundação Getúlio Vargas, 1991.

FURTADO, Celso. O mito do desenvolvimento econômico. 3 ed. Rio de Janeiro: Paz \& Terra. 1974.

GUARESCHI, Pedrinho $A$ sociologia crítica: alternativas de mudança. 8 ed. Porto Alegre: Mundo Jovem, 1986.

HARNECKER, Marta. O capital: conceitos fundamentais. São Paulo: Global, 1978. 
LEFF, Enrique. Saber ambiental: sustentabilidade, racionalidade, complexidade, poder. 3. ed. Petrópolis: Vozes, 2004.

LEI no 6.938, de 31 de agosto de 1981. Dispóe sobre a política nacional do meio ambiente, seus fins e mecanismos de formulação e aplicação, e da outras providências. Disponível em: http://legislacao.planalto.gov.br/legisla/legislacao.nsf/Viw_ Identificacao/lei\%206.938-1981?OpenDocument. Acesso em: 11 jul. 2018.

MICHAELIS. Moderno Dicionário da Lingua Português. Disponível em: https:// michaelis.uol.com.br/moderno-portugues/busca/portugues-brasileiro/sustentabilidade/. Acesso em: 8 jun. 2018.

MINISTÉRIO DO MEIO AMBIENTE. Agenda 21 Global. Disponível em: http:// www.mma.gov.br/responsabilidade-socioambiental/agenda-21/agenda-21-global. Acesso em: 8 jun. 2018.

MONTIBELLER-FILHO, Gilberto. O mito do desenvolvimento sustentável: meio ambiente e custos sociais no moderno sistema produtor de mercadorias. Disponível em: https://repositorio.ufsc.br/bitstream/handle/123456789/81183/137926. pdf?sequence=1. Acesso em: 11 jul. 2018.

ROCHA, Leonel Severo. Epistemologia do Direito: revisitando as três matrizes jurídicas. Revista de Estudos Constitucionais, Hermenêutica e Teoria do Direito (RECHTD), 2013, 5(2):141-149.

SACHS, Ignacy. Caminhos para o desenvolvimento sustentável. Rio de Janeiro: Garamond, 2002.

SILVEIRA, Clóvis Eduardo Malinverni da. Risco ecológico abusivo: a tutela do patrimônio ambiental nos Processos Coletivos em face do risco socialmente intolerável. Caxias do Sul: Educs, 2014.

VEIGA, José Eli da. Desenvolvimento sustentável: o desafio do século XXI. Rio de Janeiro: Garamond, 2010. 220 p.

VIDAL DE SOUZA, José Fernando. Uma abordagem crítica sobre o greenwashing na atualidade. Revista de Direito Ambiental e Socioambientalismo. Maranhão, v. 3, n. 2, p. 1488172, jul./dez. 2017. Disponível em: http://indexlaw.org/index.php/ Socioambientalismo/article/view/3765. Acesso em: 6 jul. 2018. 